\title{
Rubén Darío, Traductor de Gorki
}

$4^{\mathrm{N}}$ la historia de la difusión de la literatura rusa en el mundo hispá1. nico ${ }^{1}$ el papel de los diseminadores representa, desde luego, uno de los aspectos más interesantes. No ha de extrañarnos ver que los escritores más conocidos mediaron en este proceso transmisor. Entre ellos se destaca Rubén Darío. Esta faceta de su obra, sin embargo, aún queda casi completamente ignorada. Debido a la labor de Ernesto Mejía Sánchez se conoce "La Matuschka: cuento ruso", bien anotado e incorporado a los Cuentos completos de Rubén Dario. ${ }^{2}$ Se trata de uno de los muchos relatos seudorrusos escritos por muchos españoles e hispanoamericanos antes y después de I889, fecha de su publicación. ${ }^{3}$ „En "La Matuschka” Darío muestra su familiaridad con el tema ruso, en boga en ambos lados del océano. Vuelve a publicar la misma narración en Guatemala, un año más tarde, junto a materiales auténticos de Tolstoi y Turguenev,4 de acuerdo con la práctica periodística de la época. Al período chileno se remonta también el prólogo a Asonantes de Narciso Tondreau, donde Darío se refiere a la difusión e influencia de la literatura rusa:

Hace poco tiempo lo ruso preponderaba en Francia. Tolstoi, Gogol, Turguéneff, el raro y pálido Dostoiewsky, fueron traducidos a casi todas las lenguas: escritores franceses publicaron novelas rusas: el idioma se extendió más, y su terminología se puso de moda: se bebió el rojo vino de París con caviar del Volga:5

La última frase, muy rubendariana, es el mejor tributo que el poeta podía hacer a lo ruso. Señala, a la vez la necesidad de un estudio serio del papel de la literatura rusa en el desarrollo del Modernismo.

Ya que en "La Matuschka" Darío sólo reelabora elementos exóticos conocidos indirectamente, el autor no puede ser calificado de "interme-

1 En preparación un estudio con amplia bibliografía.

2 (México: Fondo de Cultura Económica, 1950), p. 121, nota 1 del editor.

3 En La Tribuna de Valparaíso, el $1^{\circ}$ de febrero, según Mejía Sánchez.

4. Correo de la Taude, 13 de diciembre de 1890, loc. sit.

5 Transcrito por Mejía Sánchez, op. cit., p. 121, n. 1 . 
diario" en este caso. Pero sí puede serlo en función de crítico y traductor. Se ha hablado de sus comentarios acerca de los autores coetáneos; se sabe que sus compañeros aumentaton sus ingresos traduciendo libros franceses al castellano; casi nadie, sin embargo, se ha fijado en que Rubén Darío - de quien no consta ninguna novela completa-- tradujo toda una obra rusa ${ }^{6}$ y que elogió al autor, Máximo Gorki, en un artículo escrito en París. Este attículo publicado en La Nación de Buenos Aires el io de febrero de 1902, por cierto, no es fácilmente accesible en su forma original, pero aquella narración, Tomás Gordeieff, con la firma de Dario - agotada por muchos años- puede ahora comprarse, baratísima, en los quioscos de las capitales latinoamericanas, en la versión facsímile de la Editora Nacional de México (I958, 34I p.)* En La Nación el nicaragüense manifiesta su admiración por el escritor tuso:

Gorki es la voz que clama en la estepa; y el mundo le escucha porque ha tenido la suerte de llegar en buena hora. Gorki es la lengua de pueblo, y se hace oír con el aliento de todo un vasto pueblo y como es hontadamente humano, su palabra es comprendida por toda la pensativa humanidad. Es vasto pensador brotado entre las muchedumbres como un alto pino en una floresta. Observa en el mundo que ha rozado gestos y enigmas. ... Su obra, que está repleta de vida, se siente, por lo tanto, llena de misterio. Es uno de esos autores, muy raros por cierto, que hacen comprender la divina afirmación de Shakespeare sobre las muchas cosas que hay en la tierra y en el cielo incomprensibles para nuestra filosofía. Es un alma inmensa que ha recogido y anotado los gritos, las violencias y los sueños de sus hermanos que sufren y caen. Es el San Juan de Dios de los malditos. ... Gorki trata asuntos que otros escritores rusos han tratado, y que tiene algunas veces semejanza con ellos, con Korolenko, por ejemplo, o con Tolstoi; pero tiene más verdad que todos, puesto que extrae de su propia carne, de su propia experiencia; ha escrito "con sangte", como diría el gran loco del Zarathustra, ${ }^{7}$

Es curioso notar, sin embargo, que en este artículo Dario no se refiere ni una sola vez a Tomás Gordeieff, una de las mejores obras de Gorki, la cual él recientemente tradujo del francés y no por encargo de la editorial.

6 Edelberto Torres se limita a mencionarlo (La dramática vida de Rubén Dario, Guatemala, 1952, p. 409); la revista soviética Inostrannaict literatura, en noventa palabras, sin firma, no aclara, desde luego, en modo alguno las circunstancias de esta traducción (1958, 3, p. 279). [íSerá traducción de la nota del peeta venezolano Carlos Augusto León, "Rubén Datío, traductor de Gorki", firmada únicamente con sus iniciales en Intercambio Culturd, México, abril-mayo de 1957, vol. IV, No 25 , p. 21?].

[* La primera edición (Barcelona-Buenos Aires-México, 1902), tiene 341 pp.; ya la segunda edición" (Barcelona-Madrid-Buenos Aires, sin fecha), 280 pp.].

7 De la reimpresión del artículo de La Nación en Opiniones (Obrar completas de Rubén Dario, I, Madrid: Afrodisio Aguado, 1950), pp. 244-5. 
Resulta indispensable, por lo tanto, estudiar la suerte de esta novela en sus versiones rusa, francesa y española, comparando las tres, atendiendo especialmente a la intervención de Rubén Darío.

Maxim Gorki comienza a escribir Foma Gordeiev en 1897 y lo publica por primera vez, por entregas, en la revista Zbizn en r899. En I90. I, la Sociedad "Znanie" reimprime tres veces la novela.9 En el mismo año I90I esta obra ya aparece en Francia, traducida, con la autorización del autor, por Mme. B. Marinovitch, bajo el título Tbomas Gordeieff.10

La rapidez de difusión de esta narración en el mundo hispánico iguala la de la versión francesa. En los primeros meses de I902, la editorial Tasso de Barcelona publica Tomấs Gordeieff, traducido por Augusto Riera.11 Poco después, ese mismo año, la casa Maucci, también barcelonesa, lanza el mismo libro en la versión de Rubén Dario. Êsta, reimpresa por Maucci varias veces, es la base de la citada edición facsímile mexicana de I958. En 1959, la editorial argentina W. 'W. Jackson imprime un volumen de lujo de obras rusas, que incluye en primer lugar el Tomás Gordeieff traducido por Dario. ${ }^{12}$ En I960, la Editorial Planeta de Barcelona publica una nueva e incompleta traducción en un castellano poco satisfactorio. ${ }^{13}$

- Las circunstancias que impulsaron a Rubén Darío a traducir Foma Gordeiev no pueden precisarse. Su artículo en La Nación indica una alta estima por el autor ruso y su obra. Tal vez quiso darla a conocer a sus compatriotas de habla española: tal vez emprendió la traducción para aliviar su estrechez eccnómica.14 Lo más probable es que fueran ambas razones las que impulsaron al poeta. Si tradujo otras obras, no las firmó. El aliciente económíco, por cierto, no pudo ser muy poderoso. En el caso de Tomás Gordeieff, traducido espontáneamente por Darío, Maucci le

8 En este estudio el ruso se transcribe en caracteres latinos según las reglas de la Biblioteca del Congreso; método en uso corriente en muchas bibliotecas hispanoamericanas, no obstarite sus características fonéticas inglesas.

9. San Petersburgo, 1901, en el cuarto tomo de Razskazy (Narraciones) del autor, versión basada en la de 1899; de alquí en adelante nos referitemos a esta edición. Desde entonces hubo muchas publicaciones de la novela, incluso en las Obras completas, como en la reciente de 18 tomos Sobranie Socbinenii (Moscú, $1960)$.

10 (París: Calmann-Lévy, 1901), 420 pp. Aquí se cita, sólo por páginas, la tercera edición, fechada 1905; por el 1929 llegó a la décima reimpresión.

11 Las primeras páginas de esta versión, según fotocopias obtenidas de la Biblioteca de Valencia, excluyen la posibilidad de una confusión con la traducción tlzbendariana.

12 Máximo Gorki, Tomás Gordeieff, trad por Rubén Darío (Buenos Aires: Editorial 'W. 'W. Jackson, 1959).

13 Maxim Gorki, Fonzá Gordeiev, trad. por Víctor Scholz, en Maestros rusos, III, ed. S. J. Arbatoff (Barcelona: Planeta, 1960).

14 Edelberto Torres, op. cit., p. 227. 
of reció ciento veinticinco francos con tal que llevara la firma del ya renombrado poeta:

Señor Don Rubén Darío.

Muy señor mío: Tengo a la vista su grata del 20 del corriente y la obra de Gorki Tomás Gordeieff que, traducida por usted, me ofrece para publicar en mi biblioteca.

Precisamente en estos días pone a la venta la casa editorial de don Luis Tasso la misma obra traducida por Augusto Riera, así es que perdemos la primacía; pero no obstante, y por complacer y atender su firma, publicaría la expresada novela, si conviene a sus intereses enajenarla, por 125 francos.

Dígame su resolución para, en caso aegativo, devolverle los originales. Sin otro particular me reitero de usted afectísimo s. s.

Manuel Maucci.15

Ciento veinticinco francos en aquel tiempo no representaban un gran caudal. En una de sus cartas a Rubén, Enrique Gómez Carrillo comenta el costo de la vida en París: "un cuarto en un hotel: 60 francos; la comida en el restaurant de la Rouchefoucauld, por ejemplo, I50. Total: 2 Io francos mensuales, como gastos indispensables". 16 En otras palabras, mucho más que los honorarios del traductor de Tomás Gordeieff. Así que el lụcro no pudo ser el motivo decisivo que empujó a Darío a traducir la novela de Gorki. ¿Sería un viejo sentimiento de afinidad entre los dos escritores; o entre el pueblo ruso y el hispano, o entre los personajes de ámbas literaturas?

El argumento de Foma Gordeiev es relativamente sencillo. Comienza con la descripción de Ignat Gordeiev, un pobre muchacho que, por su enérgica tenacidad, llega a convertirse en uno de los más ricos y respetados traficantes del Volga. Su obsesión es tener un hijo: su primera esposa muere sin dárselo y la segunda, Natalia, expira al dar luz a Tomás. Este niño tiene una sensibilidad más fina de lo común, que se desarrolla a través de sus años juveniles. Poco a poco su personalidad toma forma; el ambiente en que vive se le hace cada vez menos satisfactorio; no le puede ver razón a la vida, todo le parece sin sentido. En la búsqueda de "su lugar" en la sociedad, Tomás no puede encontrar nada ni a nadie que le pueda ayudar. Con la muerte de Ignat, Maiakin, el padrino de Tomás, toma las riendas de los negocios y trata de instruir al joven en los asuntos

15. Impreso por Alberto Ghiraldo, El arcbivo de Rubén Dario (Buenos Aires: Lasada, 1943), pp. 128-9.

16 Ibid., p. 71 . 
mercantiles. La vida comercial, sin embargo, pronto aburre a Tomás. Su mentor no quiere y no puede entenderlo y trata de obligar al joven a que siga por el camino señalado. Tomás reacciona violentamente contra esta tutela dictatorial: decide abandonarlo todo y se abisma en una vida de perdición, borracheras y orgías.

Cuatro mujeres desempeñan papeles importantes en la vida de Tomás: la primera, Pelagia, es una mujer buena y desinteresada que lo inicia en el goce carnal, y a la cual Tomás tiene que abandonar contra su voluntad; la segunda es Sofía Pavlovna Medinskaia, la maestra en la educación' sentimental de Tomás; la tercera, Sacha, una prostituta con quierı el abuso desenfrenado de la carne florece en orgías; la cuarta es Liuba Maiakin, amiga y especie de prometida de Tomás; también a ella todo le aburre, busca el "algo" que la pueda satisfacer, y al final lo encuentra en Smolin Africán, con quien se casa.

La vida del protagonista corre estéril en el desesperado afán de encontrarse a sí mismo. El punto culminante llega cuando no puede resistir más la tensión interior. En la fiesta del bautizo del barco de un comerciante, en la que toda la sociedad mercantil está presente, los sentimientos de odio, de impotencia y de venganza que Tomás siente por este grupo materialista, estallan violentamente. Lanza a la cara de cada uno de los presentes sus fechorias y crímenes. Humillados por la verdad, los traficantes hacen encerrar a Tomás en un manicomio. Cuando reaparece, se nota que no es más que un ser que está muerto moralmente, y que sólo es una sombra de sí mismo.

En la comparación textual de las tres versiones, primero se deben mencionar las omisiones mayores, tanto en la francesa como en la española. Mme. Marinovitch, al verter al francés la obra de Gorki, deja varias lagunas. La supresión más extensa es la del principio del capítulo doce.17 Gorki comienza esta parte con varias descripciones excelentes: en una noche de neblina, la embarcación en que Tomás viaja parece flotar en una atmósfera de incertidumbre, empujada por una fuerza misteriosa en dirección desconocida. Se vislumbra un paralelo entre la vida sin meta del protagonista y la marcha de este navío.

Tomás hace el viaje por el Volga para escapar de todo, y a bordo del barco se encuentra con un predicador quien, aunque pobre, parece estar satisfecho de su vida. A las preguntas que Tomás le hace sobre cómo se puede encontrar la felicidad en la vịda, el peregrino le dice que

17 Desde la página 310 hasta la 32 de la versión rusa citada. 
el hombre siempre debe responder al llamado de su alma. ${ }^{13}$ En la obra original, este episodio contribuye a reafirmar el aburrimiento que Tomás siente por todo, así como también la incesante búsqueda de su "algo".

La excelente escena del ya mencionado capítulo doce, en la que Liuba y 'Tarás se turban por la inesperada aparición de Tomás, también taita en la traducción francesa. Comienza esta parte suprimida cuando Tomás entra en la casa de los Maiakin en el momento en que los dos hermanos hablan de él de un modo poco halagador. Gorki aprovecha esta ocasión para demostrar el choque y la incomprensión entre dos espíritus opuestos: uno razonador y dinámico, representado por Tarás, y el otro, sentimental y apático, por Tomás. La conversación que se entabla con el recién venido versa sobre la felicidad y satisfacción de un ser humano. T'arás, con la rígida mentalidad de un comerciante, explica que la causa de la infelicidad de muchos hombres es que no saben trabajar y que tampoco aprecian el trabajo; que la mayoría de los hombres se creen capaces de hacer más de lo que en realidad pueden. Concluye diciendo que no se exige mucho de cada uno: tenemos que escoger el trabajo que podamos hacer bien, y si lo hacemos con dedicación y amor, hasta lo más rudo se convierte en arte. 19 Esta visión materialista de la felicidad es incomprensible y hasta molesta para Tomás. Con el deseo de enojar al complaciente mercader, Tomás le pregunta qué debe hacer un hombre a quien todo le aburre.

Al ser eliminado este pasaje, el lector de la versión francesa - y desde luego el de la española - no puede explicarse el antagonismo que existe entre Tomás y Tarás, ni tampoco la creciente aversión de Liuba, porque ésta siente que Tomás ataca injustamente a su hermano.

La otra laguna importante en la traducción de Mme. Marinovitch es la del principio del capítulo quinto, donde se describe cómo Tomás comienza a aborrecer a su padrino, quien trata de guiarlo por un camino que no le agrada. Además, la gran preocupación de Maiakin por sus negocios le hacen sospechar que quiere casarlo con su hija. Esta muchacha le agrada en algunas ocasiones y en otras le molesta, pero se entienden como buenos amigos. Los designios del viejo disgustan a Tomás y, como consecuencia, se aleja de Liuba. Otras lagunas en el texto francés no oscurecen tanto el desarrollo del libro.

La traducción rubendariana tiene sus propias lagunas. La mayor es la del capítulo cuatro, en que las veinte páginas francesas se convierten en

18 Foma Gordeiev, p. 321. En vista de la dificultad de reproducir el texto otiginal ruso, aquí se citará sólo lo más indispensable.

19 Ibid., pp. 338-9. 
siete españolas; aquí la pluma de Darío se convierte en "tijetas" y no da más que un breve resumen. Este capítulo trata del entierro del padre de Tamás; toda la ceremonia está magníficamente elaborada, tanto en el original ruso como en la versión francesa. Como muestra parcial de esta extensa supresión, notemos cómo comienza este capítulo en las dos traducciones; la francesa difiere poco del original ruso:

La mort de son père plongea Thomas dans un état de stupeur. Il éprouvait une sensation très étrange. Son âme s'était comme emplie de silence, silence lourd, immuable, qui engloutissait tous les bruits de la vie. Une quantité de gens qu'il connaissait s'agitaient autour de lui; ils arrivaient, s'en allaient, lui adressaient la parole; il répondait à tort et à travers, et leurs paroles n'éveillaient en lui aucune image, se noyaient, sans laisser de trace, dans la profondeur infinie du silence de mort qui remplissait son âme.

Il ne pleurait pas, ne se désolait pas et ne pensait à rien. Sombre et pâle, le front plissé, il écoutait, perdu dans ce silence, qui avait détruit tout sentiment, dévasté son coeur, et qui comprimait son cerveau comme dans un étau. (130)
La muerte de su padre abismó a Tomás en un estado de estupor. Gran número de conocidos se agitaban a su alrededor. No lloraba, no se desconsolaba, no pensaba en nada.20

El motivo de este acto inquisitorial puede haber sido el temor de Darío por lo macabro, al que se refieren varios comentaristas.21 Hay que subrayar que al cortar este capítulo, Darío, conscientemente o no, disminuye la dinámica personalidad de Maiakin, el personaje diametralmente opuesto al protagonista. Es aquí donde Gorki muestra las características del viejo comerciante dotado de una energía inagotable, que demuestra al disponer de todos los asuntos para el entierro de Ignat:

Mäain s'occupait de l'enterrement. Il courait, actif et pressé, d'une cham-
Maïakin se ocupó del entierro..." (110).

20 Máximo Gorki, Tomás Gordeieff, trad, por Rubén Darío (Barcelona: Maucci, 1902), p. 110. Microfilm obtenido de la Biblioteca Nacional de Madrid. De aquí en adelante las referencias a esta obra se harán por página solamente.

21 George O. Srhanzer, "Parallels between Spanish Atmerican and Russian Novelistic Themes", Hispania, XXXV (1952), pp. 45-6. 
bre à. l'autre, frappait du. talon par terre, ordonnait en maître, et tapotant amicalement sur l'épaule de son filleul... (131).

Manifiesta cinismo cuando en la solemne ocasión del entierro de su mejor amigo insiste en que el aprecio de otros se puede comprar con dinero:

-Soixante-quinze mille roubles! c'est une somme pour laquelle on peut exiger autant de personnes detrière soi. (132)

Para Maiakin la vida es un campo de batalla en el cual los rublos son los soldados (p. I35), un concepto igualmente suprimido por Darío.

En las versiones rusa y francesa de esta obra existe un equilibrio estructural entre los dos personajes, Tomás y Maiakin. La omisión casi completa de este capítulo en la versión dariana debilita este equilibrio, porque el personaje dinámico queda truncado, y esto cambia, hasta cierto punto, el tenor de la novela.

A la ya mencionada omisión en el capítulo quinto por parte de Mme. Marinovitch, Rubén Dario agrega otras, diluyendo así aún más el contenido. Suprime la descripción de las actividades en la Bolsa, donde Tomás descubre que en la vida del comercio se observa la ley del más fuerte, y esto, primero, Io atrae, porque cree que siendo fuerte como es podrá encontrar la felicidad y satisfacción buscada. Escucha ávidamente lo que le explica su padrino:

-Que veux_tu de plus encore? Chacun pour soi... Chacun cherche pour soi-même ce qu'il y a de mieux... Qu' y a-t-il de mieux? C'est d'être au-dessus de tous les autres, le premier partout. Aussi s'efforce-t-on d'atteindre la première place, l'un d'une façon, l'autre d'une autre... mais tous veulent à $n^{\prime} \mathbf{i m}$ porte quel prix être en vue, comme le clocher du village. C'est a l'élévation que l'homme est destiné... (152-3).

Pero esta filosofía de la vida pronto se desvanece pareciéndole a Tomás detestable e inhumana. 
En el mismo capítulo Darío omite descripciones cuya exquisitez estética debería de haberle atraído y que podría haber reelaborado a su manera. Uno de estos cuadros es el del salón de Sofía Pavlovna, muy al gusto de los modernistas:

Elle glissait sans bruit sur les tapis épais, lui jetait en passant un sourire ou un regard affectueux, toujours entourée de ses adorateurs, qui passaient souples comme des couleuvres, autour des différentes tables, étagères, chaises, écrans, vases dont le salon était rempli, magasin de précieux et fragiles bibelots disséminés par toute la chambre avec une négligence... (154)

El nicaragïense suprime también la descripción de los sentimientos que luchan en Tomás cuando se encuentra con la Medinskaia:

Il se taisait, contemplait sa petite personne toujours excessivement élégante, sentant bon comme une fleur, respirant une candeur virginale. Par moments, il lui venait un désir sauvage et brutal de la saisir et de l'embrasser à pleine bouche, mais aussitôt la crainte de briser dans une étreinte cette taille souple et mince l'arrêtait... (156).

La omisión de este y de otros pasajes le resta claridad y fluidez al libro.

Además de las omisiones indicadas hay otras de diferente tipo, en las que algunos diálogos aparecen resumidos. Estos cambios no son muy frecuentes y ocurren más en la versión castellana, como por ejemplo en la siguiente escena:

Ondoyante, avec des mouvements de félin, ele sel penchait vers lui et le regardait dans les yeux, de son regard sombre où brillait alors une lueur étrange.

-J'aime tant à causer avec vous, chantait-elle de sa voix mélodieuse,
Perfumada, con movimientos de felino, se inclinaba hacia él y le miraba en los ojos, con una mirada donde relucía un resplandor extraño. $Y$ al cabo de una conversación de retruécanos y juegos de palabras, él concluía por decirle con ardor: 
trainant les mots; ils magacent tous... ils sont ennuyeux, communs... Vous, vous êtes jeune, sincère... Vous non plus, vous ne les aimez pas, n'est-ce pas?

- Je ne puis les souffrir, répondait Thomas avec conviction.

-Et moi? demandait-elle doucement.

......

-Je vous aime... Je vous aime. Peut-on ne pas vous aimer?

disait-il avec ardeur.

-J'aime tant vous l'entendre dire, vous le dites si bien! vous êtes jeune... Voulez-vous embrasser ma main? (155-6).

En otras ocasiones Rubén Darío omite líneas de diálogos o párrafos enteros, lo cual priva a los pasajes del desarrollo natural y fluido de la versión rusa. A veces estas omisiones son tan patentes que el lector puede notar que falta algo; otras veces, confieren al texto cierta tosquedad o falta de claridad:

A la Bourse, il rematquait des regards malveillants et moqueurs; on lui parlait d'une façon affectée et spéciale. Une fois même, il entendit derrière lui une exclamation méprisante:

-Gordianisko! Blanc-bec!

Il comprit que ces mots s'adressaient à lui; mais il ne fit pas un mouvement pour voir qui les avait prononcés. (151)

Ces conversations avec le vieillard, toujours les mêmes, finirent par atteindre leur but. Thomas les comprit et pénétra le sens de la vie. "Il faut arriver à être au-dessus des autres", se répétait-il, et l'ambition germait dans son coeur et y jetait de profondes racines... (153)

Aquí Darío comienza la descripción con una escena que ocurre en la Bolsa; luego suprime dos páginas enteras de texto y continúa con un párrafo que

\author{
- Le [sic] amó a usted... i i La \\ amo! ¿Es posible no amarla? Pero, \\ ¿para qué? \\ — ¿Sí, V. lo ha dicho! suspiraba \\ Medinskaia satisfecha. \\ $Y$ se alejaba un poco. \\ - Me gusta tanto aírselo decir, ¡lo \\ dice tan bien! es V. joven... [sic] \\ ¿Quiere besar mi mano? (118).
}


describe los cambios emocionales que ocurren en Tomás con relación a Sofía Pavlovna. La frase "Dio parte a su sobrino..." resume la conversación entre Maiakin y su ahijado. Además, Darío parece confundir los personajes y la relación que existe entre ellos. No es Tomás quien hace las "observaciones", sino Maiakin, comentando sobre la personalidad y la reputación de la Medinskaia. Ni tampoco es Tomás sobrino de Maiakin, sino su ahijado. Toda la primera parte de este párrafo, en la versión castellana, es incoherente, porque Darío suptime mucho y luego lo resume mal.

Habiendo señalado brevemente las diferencias más obvias entre las versiones, pascmos a considerar algunos detalles. Dario tiene que traducir una obra rusa a través de una versión ya no completamente fiel a la obra original. Al cotejar los primeros párrafos de las tres versiones, notamos que la caracterización de Ignat en la versión rusa es breve, pero halagadora. En el francés, al hablar de su aspecto exterior se da a entender que es corpulento y lo mismo ccurre en español; en ruso, sin embargo, además de notar su gran estatura, se sobreentiende que su cuerpo está hermosamente formado. Esta es una apreciación estética que se pierde en el francés y consecuentemente en el español. Al hablar de la manera en que Ignat avanza hacia el fin deseado, Gorki indica que no reconoce ley alguna, lo cual denota su moralidad o falta de ella. Este aspecto de su personalidad está casi ausente en ambas traducciones.

El lector de la versión rubendariana pronto se da cuenta de que la sintaxis muchas veces no es correctamente castellana:

Mais, tout à coup, la face du vieillard prit une teinte rouge violacée, les yeux se dilatèrent et sortirent de leurs onbites, la bouche s'ouvrit et il s'en échappa un son bizarre, un sifflement rauque:

-Pff... chchch...

Puis la tête roula sur une des épaules et tout ce corps pesant glissa lentement à terre, comme si la terre l'eût attiré mystéricusement à elle. Pendarit plusieurs secondes, Thomas demeura silencieux et immobile, les yeux, remplis d'épouvante et de stupeur, fixés sur son père, puis is se précipita sur le corps, souleva la tête d'Ignat et regarda son visage. Ce visage était sombte, immobile, et les
Pero de repente la faz del anciano tonó un tinte rojo violáceo, las pupilas se dilataron y salieron de sus órbitas los ojos, se abrió la boca y se escapó un soniclo especial, un silbido renco:

-Pff... chchch...

Después la cabeza rodó sobre uno de sus hambros y todo su cuerpo pesado se deslizó lentamente a tierra, como si la tierra lo hubiese atraido mistericsamente a sí. Durante algunos segundos Tomás quedó en silencio e inmóvil, con la vista llena de espanto y terror, fija en su padre, y después se precipitó sobre el cuerpo, levantó la cabeza de Ignat y miró su rostro. Este rostro estaba sombrio, ia- 
yeux grands ouverts n'exprimaient tien, ni terreur, ni souffrance, ni joie... (128) móvil, y los ojos grandes abiertos no expresaban nada, ni terror, ni sufrimiento, ni alegría... (109-10)

El cuadro reproducido por Mme. Marinovitch es una traducción muy buena del original ruso. Mas al catejar la versión rubendariana con la francesa se nota que casi todo coincide palabra por palabra, lo cual le quita a la obra algo de su valor artístico.

Otra característica de esta versión española es que Darío traduce repetidas veces el significado más común de una palabra francesa sin considerar el contexto en que ésta se encuentra:

Il ne répondit pas. Alors Ignat, le saisissant au collet, le secoua et fit tomber de sa bouche immonde ces parcles prononcées avec terreur, doucement, presque en chuchotant. ..(7)
Entonces Ignat, cogiéndole por el cuello, le sacudió e hizo escapar de su boca inmunda estas palabras, prorunciadas con tertor, dulcemente, casi tartamudeando... (10)

Está claro que la palabra "dulcemente" no corresponde al "doucement" francés en este caso. En otras ocasiones el "dulcemente" de Darío tiene el significado de "furtivamente", o "sin decir una palabra", etcétera.

Otros ejemplos de palabras mal traducidas son: "un prêtre défroqué" (5) - "un sacerdote sin escrúpulos" (9); "presque en chuchotant" (7) - "casi tartamudeando" ( IO); "une porte vitrée qui grinçait" (26) - "una puerta de cristales que giraba" (26); "une force immense" (4I) — "una fuerza intensa" (38); "ondoyante" (I55)-_"perfumada" (r I8); "sons bizarres" (I66) — "sones bizantinos" (I 24); "lèvres épaisses" (I8I) - "labios espesos" (I37); "la contradiction irritait" (316) "la contradicción visitaba" (252); "parlait simplement" (338) - "hablaba seguramente" (27I); "devant les vitrines" (367) - "ante las víctimas" (295) ... Huelga decir que Rubén Dario obra con descuido y no se molesta en revisar lo escrito.

Además de las palabras mal traducidas, la versión rubendariana está salpicada de vocablos franceses. Hasta los nombres de los personajes aparecen muchas veces en la forma afrancesada: "Jacob", "Antheisa", "Efime", Sofka", "Thomka" y "Virgile". En otras ocasiones utiliza la misma palabra francesa en el texto castellano: "parterre" (328) - "parterre" (262) ; "vipère" (348) — "vípera" (279); "troupe" (362) - "troupe" (29I). El más interesante de estos galicismos lexicográficos, sin embargo, es el empleo, que hace Darío, de una palabra francesa en la descripción de un paisaje cuando esa palabra no aparece en el texto francés: 
D'un côte, les bords escarpés se reflètent en de sombres tableaux, pendant que, de l'autre, brillent, comme une merveilleuse parure, l'or des plages de sable et le velouts des vertes prairies. (39)
Por un lado los bordes escarpados * se reflejan en sombríos cuadros, mientras que brilla en el otro, como una maravillosa toilette, el oro de las playas de arena y el terciopelo de las verdes praderas. (37)

Rubén Darío en su traducción reemplaza una palabra francesa con otra, lo cual, junto con las otras indicaciones de afrancesamiento en el libro, confirma el galicismo mental que se le ha atribuido.

Algunos errores lexicográficos se encuentran ya en la versión francesa; Mme. Marinovitch se equivoca al traducir la palabra rusa "Shalyi" (audaz, p. 2) por "Toqué" (p. 2), que se convierte en "chiflado" (p. 6) en la versión de Darío. Otros ejemplos son: "razstriga-diakon" (p. 4) "un prêtre défroqué" (p. 5); "plotovschiki" (p. 30) - "les mariniers" (p. 40).

Pasemos a considerar las diferencias de carácter más creador que aparecen en las descripciones plásticas, los proverbios, los poemas y las canciones.

Las descripciones de Gorki, por lo general, no son muy minuciosas, pero sí evocadoras. Con breves frases crea en la imaginación del lector un conjunto panorámico de gran belleza lírica, la cual, desgraciadamente, no podemos reproducir aquí. El trozo siguiente demuestra que Dario logra, hasta cierto punto, reproducir el lirismo encontrado en el francés:

Sur le versant en pente douce s'étalent à présent les verts tapis des semailles d'automne, les bandes rousses de la terre en friche et les bandes noires des terres labourées, prêtes à recevoir le blé. Dans l'air, les oiseaux tourbillonnent comme de petits points noirs et se détachent nettement sur le bleu pur du ciel. On aperçoit, dans le lointain, un troupeau minuscule, semblable à un jouet, avec la silhouette du berger appuyé sur son bâton et regardant la rivière. (40-1)
En las vertientes se ven ya los verdes tapices de las siembras de otoño, la tierra sin labrat y los surcos negros de las tierras dispuestas a recibir el trigo. En el aire, los pájaros se arremolinan como puntitos negros y se destacan, de un modo neto, del azul puro del cielo. Allá a lo lejos se percibe un rebaño minúsculo, parecido a un juguete, y la silueta del pastor, apoyado en su tranca y mirando al río. (38)

Parte de la gracia y de la espontaneidad de la novela del escritor eslavo se debe a la presencia de los proverbios populares. En estos cortos decires se refleja la íntima sencillez del pueblo tuso y es curioso notar 
cómo Mme. Marinovitch y Rubén Dario los adaptan al francés y al español. Para mejor advertir cómo éstos son modificados al pasar de idioma a idioma, notemos algunos de ellos:

"Liubi zhenu, kak dushru, triasi yeyo, kak grushu," (9)

(Ama a tu mujer como a tu alma pero sacúdela como a un peral)

"Aime ta femme comme ton âme et secoue-la comme un poirier," (II)

"Ama a tu mujer como a tu alma y sacúdela como a un peral," (I4)

"Ty ishcho shchonok, rano tebe basom laiat," (88)

(Todavía eres cachorro, es temprano para que ladres con voz de bajo)

'Tu n'es qu'un jeune chien, il n'est pas encore temps de prendre une grosse voix!" (III)

"No eres más que un perro joven y no es aún hora de alzar el gallo, (95)

"Pianitsa-prospitsia, a durak-nikogda," (92)

(El borracho se desembriagará durmiendo pero el tonto nunca)

"I'ivrogne cuve son vin et se réveille ensuite, tandis que l'imbécile..." (II6)

"El borracho traga vino y se despierta en seguida, mientras que el imbécil..." (99)

"Voti i Valaamova oslitsa zagovorila!" (25I)

(La burra de Balaam se puso a hablar)

"L'ânesse qui prend̆ une voix humaine!" (277)

"iLa burra tomando voz humana!" (217)

"Kak vorona na zabore," (336)

(Como un cuervo en la cerca)

"Je suis la mouche du coche," (364)

"Soy la mosca de la cochina," (293)

En ambas traducciones los proverbios rusos se convierten, como se puede ver, en seudorrefranes.

En el capítulo doce, el original ruso describe el coro de los trabajadores que acompañan su labor con canciones (pp. 334-5). Mme. Marinovitch sólo menciona que cantan el estribillo de una canción; luego omite el verdadero estribillo e inventa otro, utilizando las palabras que marcan e! ritmo del trabajo. Después, tampoco menciona que los dos versos siguientes emanan de la bodega, y cambia de nuevo el estribillo, utilizando el último verso de la canción: 
... ils l'accompagnaient du refrain d'une chanson dont le rythme était très vif:

Les gros merchands au cabaret

Boivent des liqueurs chères... chantait en récitatif, le solo de la troupe.

Puis le choeur reprenait la suite. Des voix graves chantaient:

Ça-va, ça-va! (362-3)
... ellos les acompañaban con el estribilla de una canción, cuyo ritmo era muy vivo:

Los negociantes ricos en la taberna.

Beben licorés de los más caros... cantaba él (sic) solo de la troupe.

Después el coro seguía. Voces graves cantaban:

¡Más caros, más caros! (291-2)

Rubén Darío sigue fielmente la versión francesa cambiando únicamente el "ça-va" de ella por las palabras "más caros" de los primeros dos versos.

En otra ocasión Mme. Marinovitch ( $\mathrm{Pp} .24 \mathrm{I}$ y 275) y consecuentemente Darío (pp. 187 y 216 ), traducen de dos maneras distintas el texto de una canción que aparece dos vóces en el libro. Parece que la francesa olvidó que había traducido esos versos antes.

No obstante los defectos de las traducciones, el éxito de la novela fue indudable. Pero probablemente no se debió ni a la fama del autor ni a la del traductor. El lector hispano encontró algo en ella que le era conocido y por lo tanto grato. La falta de voluntad del protagonista lo asemeja a los personajes abúlicos de las letras hispánicas. Este paralelismo ya fue señalado en un estudio anterior.21 La abulia en las letras hispanoamericanas definida por Arnold Chapman como:

extreme emotional sensitivity, inability to adjust to an unfriendly environment, and artested development; middle class values: drink as an instrument of self-destruction... and a slow death.22

caracteriza admirablemente a Tomás, quien no puede ajustarse a su ambiente. Constantemente está buscando "algo", algo que no puede precisar.

-Pienso a veces, pienso... y los pensamientos se posan agrupados en mi alma, como moscas en liga... Después, bruscamente, todo se desvanece, desaparece como por encanto y el alma queda vacía, negra y glacial como una cueva... inada subsiste! Eso hace temblar... como si no se fuese hombre, sino un abismo sin fondo... ¿Qué me falta? (201)

Todo lo que Tomás prueba, le desagrada, le aburre: el trabajo de mercader, las orgías con las que trata de olvidar. Hay un momento en su vida en que parece encontrar lo que busca: cuando participa momentáneamente

22 "The Perdido as a Type in Some Spanish American Novels" PMLA, IXX $(1955)$, p. 36. 
en el trabajo de sacar a flote el lanchón hundido (196). Sin embargo, el final aparece claro en la última página; leemos:

Hace algún tiempo Tomás ha reaparecido en las calles de la ciudad. Está ajado y medio loco. Casi continuamente borracho, se le ve ya sombrio, el ceño fruncido y la cabeza baja, ya sonriente con la risa lamentable y triste de los alienados. (341)

Aunque el aspecto de la abulia está claramente delineado en ambas traducciones el desarrollo de los personajes en ellas parece algo cortado a causa de las omisiones. En el original ruso, la abulia es el tema principal; el mismo Maxim Gorki atestigua que quería crear el tipo de personaje abúlico. En una carta a un amigo, al hablar de Foma Gordeiev, dice:

[la novela] debe constituir un cuadro extenso y representativo de lo presente como trasfondo de un hombre, enérgico y fuerte que debe luchar violentamente en la búsqueda de un trabajo que corresponda a sus fuerzas y de espacio para su energía. Se siente enclaustrado: la vida le oprime; se da cuenta que en ella no hay lugar para héroes, cosas insignificantes lo derriban, tal como si Hércules, derrotando hidras, hubiese sido vencido por una nube de mosquitos. Fomá no es un mercader típico: representante de la clase; es $\tan$ sólo un hombre vigoroso, que desea una vida libre y se siente oprimido por el marco de la vida contemporánea. 23

Además de Tomás, otros personajes de la novela manifiestan ciertos tipos y diferentes grados de abulia: Natalia, madre de Tomás; Sacha, amante del protagonista; la Medinskaia y Nicolás Ejoff;24 y hasta cietto punto, Liubov, hija de Maiakin. En otras palabras, Gorki ha creado entre su personaje principal y los menores toda una gama de abúlicos.

T'eniendo en cuenta lo anterior, puede afirmarse que las traducciones de Foma Gordeiev, tanto al francés como al español, adolecen de muchos defectos. Carecen de la fluidez, la armonía y el equilibrio de la obra original. El desarrollo de los personajes y las relaciones que los unen aparecen más confusos y el lector en algunas ocasiones llega a percibir un estilo y una presentación algo quebrados. En ambos casos, la novela está traducida con poco esmero; los dos traductores son muy arbitrarios y descuidados en su labor: suprimen muchas páginas de texto y en muchos casos no transmiten correctamente el efecto deseado por el novelista ruso. Sin embargo, este tipo de traducción era corriente en aquella época, según Portnoff:

23 Sobranie socbinenii, III, 464. La traducción al español es de los autores.

24. Es interesante notar que el cuentista chileno, Baldomero Lillo, empleó este apellido como seudóninno en algunos de șus escritos. 
Todas estas traducciones son muy malas. El traductor o traductores han vertido al español las palabras; pero el espíritu de la obra se ha quedado en el original. Ni en Francia, ni en España respetaron siquiera la totalidad del texto original.25

Comparada con el original de Foma Gordeiev, la versión española no es más que su sombra, pero esto no llegaron a saberlo los que se entusiasmaron con esta "refracción" de la realidad rusa. Por lo tanto, la mediación de Darío contribuyó a la difusión de la literatura eslava y a la consagración de Gorki.

El éxito de la traducción de Foma Gordeiev señala a Darío como intermediario importante entre la literatura rusa y la hispana. Además hay que considerar el aspecto abúlico de la novela, intensificado en la versión de Darío, como aportación al tema de la abulia en la literatura hispánica, tan importante a principios del novecientos.

State University of New York at Buffalo

GEORgE O. SCHANZER BORIS GAIDASZ

25 George Portnoff, La literatura rusa en España (New York: Instituto de las Españas, 1932), p. 40 . 
